\title{
EFEKTIFITAS FUNGI MIKORIZA ARBUSKULA DAN PLANT GROWTH \\ PROMOTING BACTERIA TERHADAP PERTUMBUHAN Aquillaria crassna
}

Effectiveness of arbuscular mycorrhizal fungi and plant growth promoting rhizobacteria on growth of Aquillaria crassna

Ragil S. B. Irianto

Pusat Penelitian dan Pengembangan Hutan

Jl. Gunung Batu No. 5, Bogor, Indonesia

e-mail: ragil.irianto@gmail.com

Tanggal diterima : 15 Juni 2015, Tanggal direvisi : 1 Juli 2015, Disetujui terbit : 1 Oktober 2015

\begin{abstract}
Aquilaria crassna is an exotic plant producing agarwood. This research aimed to observe arbuscular mychorrhizal fungi (AMF) and plant growth promoting rhizobacteria (PGPR) effectiveness on growth of $A$. crassna in nursery and field. Experiments were arranged in a randomized completed design in the nursery, and in a randomized completed block design in the field. Seedlings were inoculated with Glomus ACA, Glomus SWM, PGPR, Glomus ACA+PGPR, and uninoculated seedlings as a control. Result showed that inoculation with Glomus ACA, Glomus SWM, dan PGPR could accelerated height and diameter of 8-months-old seedling significantly as much as 127, 128, 94; dan 51, 52, 39\% compared to control. Inoculation Glomus ACA, Glomus SWM, still could be accelerated plant growth of height and diameter of 6-months-old young trees as much as $67.81 \%$ and $66.76 \%$ compared to control.
\end{abstract}

Keywords: Aquilaria crassna, Glomus, PGPR, AMF, seedling, nursery, field

\begin{abstract}
ABSTRAK
Aquilaria crassna merupakan salah satu tanaman eksotik penghasil gaharu. Tujuan dari penelitian ini adalah untuk mengetahui efektivitas fungi mikoriza arbuskula (FMA) dan plant growth promoting rhizobacteria (PGPR) terhadap pertumbuhan bibit di persemaian dan tanaman di lapang. Penelitian di pesemaian diatur dalam rancangan acak lengkap dan di lapang dengan rancangan acak kelompok dengan perlakuan kontrol, Glomus ACA, Glomus SWM, Glomus ACA + PGPR dan PGPR. Hasil penelitian menunjukkan bahwa perlakuan inokulasi Glomus ACA, Glomus SWM, dan PGPR meningkatkan tinggi dan diameter bibit umur 8 bulan secara signifikan berturut-turut sebesar 127 , 128, 94; dan 51, 52, 39\% dibandingkan dengan kontrol. Inokulasi Glomus ACA, dan Glomus SWM dapat meningkatkan pertumbuhan tinggi dan diameter tanaman muda secara nyata sebesar $67,81 \%$ dan $66,76 \%$ dibandingkan dengan kontrol.
\end{abstract}

Kata kunci: Aquilaria crassna, Glomus, PGPR, FMA, bibit, pesemaian, lapangan

\section{PENDAHULUAN}

Gaharu telah lama dikenal dalam bidang kesehatan oleh masyarakat Hindu dan Islam. Disamping untuk pengobatan, gaharu juga digunakan sebagai parfum dan asap wewangian dalam upacara-upacara keagamaan agama
Islam, Hindu dan Budha. (Barden et al., 2014).

$$
\text { Aquilaria crassna Pierre ex }
$$

Lecomte merupakan salah satu tanaman penghasil gaharu yang memiliki penyebaran alami (indigenous) di Kamboja, Laos, Thailand dan Vietnam (IUCN, 2015). Di Indonesia terdapat enam 
jenis Aquilaria yaitu $A$. beccariana, $A$. cumingiana, A filaria, A. hirta, A. malaccensis, dan A. microcarpa (Soehartono, 1997). Diduga A. crassna diintroduksikan ke Indonesia sekitar tahun 1990an. Indikasinya adalah ditemukan adanya tanaman $A$. crassna yang paling tua berumur dua puluh tahunan yang tumbuh di Darmaga, Kabupaten Bogor. Jenis-jenis tanaman tersebut dapat menghasilkan gaharu dengan kualitas yang cukup bagus.

Eksploitasi tanaman gaharu secara besar besaran yang dilakukan sejak puluhan tahun yang lalu menyebabkan populasi tanaman ini menurun secara drastis dan mengakibatkan tanaman gaharu Indonesia masuk dalam kategori terancam menurut IUCN Red List category (Bardan et al., 2014). Tanaman gaharu yang semakin langka dan memiliki nilai ekonomi yang tinggi tersebut telah merangsang masyarakat untuk menanam dalam skala yang cukup luas di Pulau Sumatera, Kalimantan, Bali, Nusa Tenggara, dan Jawa.

Pada umumnya tanah-tanah di luar Jawa memiliki lapisan top soil tipis, kandungan bahan organik rendah, miskin unsur hara dan masam. Pada tanah-tanah yang masam ini unsur $\mathrm{P}$ akan menjadi kendala dikarenakan unsur ini akan terkhelat oleh $\mathrm{Al}$ dan $\mathrm{Fe}$ sehingga tidak dapat diserap oleh akar tanaman tanpa bantuan mikrob tanah yang menguntungkan, misalnya Fungi Mikoriza Arbuskular (FMA). Penanaman tanaman penghasil gaharu oleh masyarakat umumnya hanya memberikan input yang minim yaitu pupuk kandang dan pupuk kimia, dan belum menggunakan inokulum mikrob tanah yang menguntungkan. Penggunaan inokulan mikrob atau yang sering disebut sebagai biofertilizer merupakan cara yang menjanjikan untuk meningkatkan pertumbuhan tanaman. Karena FMA dan Plant Growth Promoting Rhizobacteria (PGPR) mampu meningkatkan ketersediaan unsur hara bagi tanaman, terutama $\mathrm{N}$ dan $\mathrm{P}$ (Eichler et al., 2004; Yasmin et al., 2007; Shaharoona et al., 2008; Richardson et al., 2011). Sumber utama mikrob untuk biofertilizer adalah kelompok yang disebut PGPR, fungi-fungi yang menguntungkan dan ganggang hijau biru (cyanobacteria) (Almethyeb et al., 2013). Selain meningkatkan penyerapan unsur hara, inokulasi mikrob juga dapat membantu melindungi tanaman dari serangan patogen tular tanah (Thrane et al., 2000) serta menghasilkan hormon-hormon pertumbuhan (phytohormones) (Kannan dan Sureendar, 2009).

Tujuan dari penelitian ini adalah untuk mengetahui efektivitas aplikasi FMA Glomus ACA, Glomus SWM, PGPR dan Glomus ACA + PGPR terhadap 
pertumbuhan bibit A. crassna di pesemaian dan tanaman di lapang.

\section{BAHAN DAN METODE}

\section{A. Tempat dan waktu penelitian}

Penelitian ini terdiri dari dua tahap yaitu penelitian tahap pesemaian dan tahap lapang. Penelitian tahap pesemaian terdiri dari kegiatan inokulasi FMA dan PGPR, serta kegiatan laboratorium seperti penghitungan persentase kolonisasasi akar, proses pengeringan dan penimbangan biomasa dilaksanakan di Laboratorium Mikrobiologi Hutan, Pusat Penelitian dan Pengembangan Hutan.

Penanaman bibit A. crassna dilakukan pada awal bulan Januari 2011 di Kawasan Hutan Dengan Tujuan Khusus (KHDTK) Carita.

\section{B. Bahan dan alat}

Bahan-bahan yang digunakan dalam pelaksanaan penelitian ini adalah sebagai berikut: kantong plastik hitam (polybag, ukuran $10 \mathrm{~cm} \times 12 \mathrm{~cm}$ ), kantong plastik transparan ukuran $100 \mathrm{~cm}$ x 140 $\mathrm{cm}$, bak perkecambahan (ukuran $44 \mathrm{~cm} \mathrm{x}$ $24 \mathrm{~cm} \times 20 \mathrm{~cm}$ ), basamid, tanah subsoil pada kedalaman 20-40 cm, inokulan (PGPR, Glomus ACA dan Glomus SWM), biji $A$. crassna dan paranet $60 \%$.

Alat-alat yang digunakan dalam penelitian ini adalah kaliper, penggaris, mikroskop, kamera, embrat, dan timbangan analitik.

\section{Metode penelitian}

\section{Perkecambahan biji dan persiapan} media

Biji tanaman pengahasil gaharu $A$. crassna diambil dari buah yang sudah masak dari pohon induk di DarmagaBogor. Polong biji tanaman penghasil gaharu dikeringanginkan di ruangan sampai biji keluar dari polong. Biji disebarkan secara merata pada media perkecambahan zeolit yang steril (zeolit disterilkan dengan alat autoklaf pada suhu $121^{\circ} \mathrm{C}$, tekanan $1 \mathrm{~atm}$ selama 30 menit) pada bak perkecambahan plastik (ukuran $45 \mathrm{~cm}$ x $30 \mathrm{~cm} \times 20 \mathrm{~cm}$ ), kemudian ditutup dengan ditaburi media zeolit setebal $3 \mathrm{~mm}$.

Bak perkecambahan tersebut disimpan dalam rumah kaca, kelembaban media tersebut dijaga dengan cara penyiraman air dengan alat semprot kecil (1 L) pada pagi dan sore hari.

Kecambah $A$. crassna yang tumbuh pada bak kecambah dipindah ke dalam polybag yang telah diisi dengan media tumbuh steril yang berupa campuran tanah yang dicampur dengan sekam padi (19:1 v/v) untuk perbaikan aerasi dalam media. Inokulan FMA diletakkan pada lubang tanam kecambah sebanyak $5 \mathrm{~g}$. 


\section{Cara sterilisasi media dan perbanyakan inokulan}

Sterilisasi media tumbuh bibit dengan cara menambahkan $200 \mathrm{~g}$ basamid ke dalam satu $\mathrm{m}^{3}$ media kemudian dicampur dengan cara diaduk dengan cangkul sampai tercampur secara merata. Media tersebut kemudian disungkup secara rapat dengan plastik tranparan selama dua minggu.

Glomus ACA (berasal dari rhizosfer Acacia auriculiformis PT Bukit Asam, Sumatera Selatan), dan Glomus SWM (berasal dari rhizosfer Swietenia macrophylla PT Musi Hutan Persada, Sumatera Selatan) diperbanyak pada pot kultur plastik (230 ml) dengan media zeolit dan tanaman inang Prueraria javanica selama 4 bulan. Pada umur 4 bulan, tanaman $P$. javanica dipotong pada permukaan media bibit, akar-akarnya dipotong-potong sekitar $0.5 \mathrm{~cm}$ dan dicampurkan kembali dengan media zeolite asalnya secara merata. Kedua inokulan tersebut mengandung propagul aktif seperti miselia, akar terinfeksi dan spora. Kepadatan rata-rata spora masingmasing inokulan per $5 \mathrm{~g}$ adalah sebagai berikut Glomus ACA (75 spora), dan Glomus SWM (50 spora).

\section{Penanaman bibit di lapangan}

Lubang tanam dengan jarak tanam $5 \mathrm{~m} \times 5 \mathrm{~m}$ dipersiapkan pada awal bulan
November 2010, kemudian diisi dengan pupuk kandang ayam pedaging dengan ukuran $2 \mathrm{~kg}$ dan dibiarkan selama 4 minggu. Pada awal bulan Januari 2011 bibit tanaman A. crassna ditanam.

\section{Pengamatan pertumbuhan dan}

kolonisasi akar

Variabel pertumbuhan bibit tanaman gaharu yang diamati di pesemaian yaitu tinggi, diameter, berat kering bibit, dan kolonisasi akar. Sedangkan variabel pertumbuhan tanaman muda umur 8 bulan di lapang yang diamati adalah tinggi dan diameter.

Akar bibit tanaman yang dipanen direndam dalam larutan 10\% $\mathrm{KOH}(\mathrm{w} / \mathrm{v})$, kemudian direndam dengan larutan 10\% $\mathrm{HCl}$ (Brundrett et al., 1996). Akar-akar tersebut kemudian diwarnai dengan 0,05\% tripan blue. Persentase kolonisasi akar dihitung dengan metode Giovannetti dan Mosse (1980).

\section{Ketergantungan bibit terhadap mikoriza}

Ketergantungan bibit tanaman penghasil gaharu terhadap mikoriza (MD, Mycorrhizal Dependency) dihitung berdasarkan rumus yang dikemukakan oleh Plenchette et al. (1983):

\footnotetext{
$\mathrm{KBTM}=\frac{\text { bkt bermikoriza-bkt kontrol }}{\text { bkt bermikoriza }} \times 100 \%$ Keterangan :

KBTM : Ketergantungan Bibit Terhadap Mikoriza

Bkt : berat kering tanaman
} 


\section{Rancangan penelitian dan analisis data}

Rancangan penelitian pembibitan di pesemaian adalah Rancangan Acak Lengkap dengan lima perlakuan (kontrol, Glomus ACA, Glomus SWM, PGPR, Glomus ACA + PGPR), sedangkan rancangan penelitian yang digunakan pada saat penanaman di lapang adalah Rancangan Acak Kelompok (RCBD) dengan lima perlakuan, dan jumlah ulangan tiga dan masing-masing ulangan terdiri dari 9 tanaman.

Data dianalisis dengan bantuan program statistika JMP Start Statistics 8, data yang menunjukkan perbedaan yang nyata diuji lebih lanjut dengan uji Tukey (Sall et al., 2005).

\section{HASIL DAN PEMBAHASAN}

\section{A. Efektiftas inokulasi di pesemaian}

Inokulasi tunggal Glomus ACA, Glomus SWM dan PGPR dapat meningkatkan pertumbuhan tinggi dan diameter bibit $A$. crassna umur 8 bulan di pesemaian secara nyata $(p<0,0001)$ berturut-turut sebesar $127 ; 128 ; 94$; dan 51, 52,39\% dibandingkan dengan kontrol (Tabel 1). Perlakuan inokulasi antara Glomus ACA dan Glomus SWM tidak menunjukkan perbedaan yang nyata diantara keduanya dalam parameter tinggi dan diameter, hal ini menunjukkan bahwa kedua jenis FMA tersebut mempunyai tingkat efektivitas yang sama.

Tabel 1. Pengaruh inokulasi FMA dan PGPR terhadap pertumbuhan tinggi dan diameter bibit tanaman penghasil gaharu $A$. crassna umur 8 bulan di pesemaian

\begin{tabular}{lccc}
\hline \multicolumn{1}{c}{ Jenis FMA } & Tinggi $(\mathrm{cm})$ & Diameter $(\mathrm{mm})$ & Kolonisasi Akar $(\%)$ \\
\hline Glomus ACA & $62,444 \mathrm{a}(127)$ & $5,052 \mathrm{a}(51)$ & $70,78 \mathrm{a}(199)$ \\
Glomus SWM & $62,539 \mathrm{a}(128)$ & $5,062 \mathrm{a}(52)$ & $74,62 \mathrm{a}(215)$ \\
PGPR & $53,373 \mathrm{~b}(94)$ & $4,657 \mathrm{~b}(39)$ & $60,25 \mathrm{a}(154)$ \\
Glomus ACA + PGPR & $24,707 \mathrm{c} \mathrm{(-10)}$ & $3,379 \mathrm{c}(1)$ & $23,71 \mathrm{~b}(17)$ \\
Kontrol & $27,470 \mathrm{c}(0)$ & $3,339 \mathrm{c}(0)$ & $23,30 \mathrm{~b}(0)$ \\
\hline
\end{tabular}

Keterangan:

1. Angka yang diikuti oleh huruf yang sama menunjukkan tidak ada perbedaan yang nyata pada taraf $\mathrm{p}=0.05$ berdasarkan uji Tukey

2. Angka dalam tanda kurung adalah persentase peningkatan suatu variabel pengamatan dibandingkan dengan kontrol

Perlakuan inokulasi FMA tunggal

Glomus ACA dan Glomus SWM dan inokulasi ganda antara Glomus ACA dan PGPR dapat meningkatkan berat kering akar, pucuk, total bibit A. crassna secara nyata berturut-turut sebesar 143, 133, 66 ; 174 193, 119; dan 164, 173 dan 102 dibandingkan dengan kontrol (Tabel 2). 
Tabel 2. Pengaruh inokulasi FMA dan PGPR terhadap nisbah pucuk akar, tingkat ketergantungan terhadap mycorrhiza, berat kering akar, pucuk, total bibit tanaman penghasil gaharu umur 8 bulan di lapangan

\begin{tabular}{|c|c|c|c|c|c|}
\hline Jenis FMA & BKA (g) & $\mathrm{BKP}(\mathrm{g})$ & $\mathrm{BKT}(\mathrm{g})$ & $\begin{array}{c}\text { Nisbah } \\
\text { Pucuk } \\
\text { Akar }\end{array}$ & $\begin{array}{c}\text { TKTM } \\
(\%)\end{array}$ \\
\hline Glomus ACA & 1,3385 a (143) & $3,1225 \mathrm{ab}(174)$ & 4,4610 a (164) & 2,3 & 62 \\
\hline Glomus SWM & 1,2842 a (133) & 3,3344 a (193) & 4,6176 a (173) & 2,6 & 63 \\
\hline Glomus ACA + PGPR & 0,9149 b (66) & 2,4975 b (119) & $3,4124 \mathrm{~b}(102)$ & 2,7 & 51 \\
\hline PGPR & 0,3589 c $(-35)$ & 0,5913 c (-48) & $0,9501 \mathrm{c}(-44)$ & 1,6 & \\
\hline Kontrol & $0,5512 \mathrm{c}(0)$ & 1,1378 с (0) & $1,6890 \mathrm{c}(0)$ & 2,1 & 0 \\
\hline
\end{tabular}

Perlakuan FMA tunggal Glomus ACA dan Glomus SWM dapat meningkatkan pertumbuhan tinggi, diameter bibit (Tabel 1) dan berat kering akar, pucuk dan total bibit A. crassna (Tabel 2). Hal ini menunjukkan adanya konsistensi dengan pertumbuhan tinggi dan diameter tanaman muda umur 6 bulan di lapang (Tabel 3). Peningkatan tersebut karena FMA mampu membantu tanaman dalam menyediakan unsur-unsur hara, terutama $\mathrm{P}$ yang penting dalam proses metabolisme tanaman. Hasil ini sejalan dengan penelitian-penelitian sebelumnya pada tanaman Alstonia angustiloba, A. scholaris, Tectona grandis, Dyera polyphylla dan A. filaria (Irianto et al., 2015a; Irianto et al. 2015b dan Irianto dan Santoso, 2009c, dan Turjaman et al., 2006). Peningkatan pertumbuhan bibit akibat inokulasi mikoriza tersebut dapat dibuktikan dengan persentase kolonisasi pada bibit yang diiinokulasi dengan FMA Glomus sp1 dan Glomus SWM dimana terjadi peningkatan persentase kolonisasi sebesar 199 dan 215\% dibandingkan dengan kontrol (Tabel 2).

Tinggi rendahnya persentase kolonisasi akar dapat merefleksikan adanya hifa eksternal yang terdeteksi pada sistem perakaran tersebut, maka semakin tinggi pula hifa ekstrernal yang muncul di perakaran. Hifa eksternal inilah yang memperluas volume tanah yang dijadikan sebagai daerah serapan unsur hara. Dengan semakin besarnya volume tanah sebagai daerah serapan akan meningkatkan serapan unsur-unsur hara bagi tanaman seperti terutama unsur $\mathrm{P}$ dan unsur unsur lainnya seperti N, K, Ca, dan Mg (Sieverding, 1991).

Kualitas bibit tanaman ditentukan juga oleh nisbah pucuk-akar (NPA). Nisbah pucuk-akar bibit tanaman $A$. crassna umur 8 bulan untuk semua perlakuan kecuali inokuasi PGPR berkisar pada rentang 2,3 - 2,7 (Tabel 2). Perlakuan inokulasi tunggal FMA Glomus ACA dan Glomus SWM dan inokulasi ganda antara Glomus sp1 dan PGPR memiliki nilai nisbah lebih besar 
dibandingkan dengan kontrol dan inokulasi ganda antara Glomus ACA dan PGPR, hal tersebut menandakan bahwa perlakuan inokulasi dapat meningkatkan pertumbuhan biomas pucuk lebih besar dibandingkan dengan biomas akar. Peningkatan NPA pada rentang 2,3 - 2,7 masih dalam kisaran NPA yang optimal sebagai bibit yang berkualitas baik menurut klasifikasi Duryea dan Brown (1984).

Nilai tingkat ketergantungan bibit tanaman (mycorrhizal dependency, MD) A. crassna terhadap FMA Glomus ACA, Glomus SWM dan Glomus ACA + PGPR berturut-turut adalah 62, 63 dan 51\% (Tabel 2). Nilai MD tersebut termasuk tinggi menurut klasifikasi yang dikemukakan oleh Cruz et al. (1995). Nilai MD yang tinggi tersebut merupakan indikator bahwa perlakuan inokulasi FMA di pembibitan sangat diperlukan untuk mendapatkan bibit dengan tingkat kesehatan dan vigor yang baik dan menjamin tingkat keberhasilan hidup bibit setelah ditanam di lapang semakin besar.

\section{B. Efektifitas Inokulasi di Lapangan}

Pengaruh inokulasi Glomus ACA, Glomus SWM dan inokulasi ganda antara Glomus ACA dan PGPR yang diberikan pada saat di pesemaian masih memberikan respon positif pada pertumbuhan tinggi dan diameter tanaman muda A. crassna umur 6 bulan setelah ditanam di lapang secara nyata berturut turut sebesar 67,81 , 74; dan 66, 76, 80\% dibandingkan dengan kontrol (Tabel 3). Peningkatan pertumbuhan ini sesuai dengan respon posistif pada parameter berat kering akar, pucuk dan total bibit tanaman A. crassna umur 8 bulan di pesemaian (Tabel 2), juga sesuai dengan respon pada pertumbuhan tinggi dan diameter bibit A. crassna di pesemaian dengan pengecualian pada perlakuan inokulasi ganda antara Glomus ACA dan PGPR yang memberikan respon negatif (Tabel 1).

Hasil pertumbuhan tersebut sesuai dengan penelitian pada tanaman muda Alstonia scholaris, Alstonia angustiloba, Olea europaea L. dan Capsicum chinense di lapang (Irianto, 2015a; Irianto, 2015b; Estaun et al., 2003: dan Constantino et. al., 2008). Pertumbuhan tanaman di lapang yang mendapat perlakuan tersebut di atas dipengaruhi oleh beberapa faktor antara lain kondisi tanah, iklim dan interaksi dengan mikroba indigen (Lucy et al., 2004 In Contantino et al., 2008). 
Tabel 3. Pengaruh Inokulasi FMA dan PGPR terhadap Pertumbuhan Tinggi dan Diameter Tanaman Muda Penghasil Gaharu Umur 6 bulan di Lapang

\begin{tabular}{lcc}
\hline \multicolumn{1}{c}{ Jenis FMA } & Tinggi $(\mathbf{c m})$ & Diameter $(\mathbf{m m})$ \\
\hline Glomus ACA & $62,9510 \mathrm{a}(67)$ & $7,1979 \mathrm{a}(66)$ \\
Glomus SWM & $68,1959 \mathrm{a}(81)$ & $7,6057 \mathrm{a}(76)$ \\
Glomus ACA + PGPR & $65,4839 \mathrm{a}(74)$ & $7,8050 \mathrm{a}(80)$ \\
PGPR & $46,2464 \mathrm{~b}(23)$ & $5,1053 \mathrm{~b}(18)$ \\
Kontrol & $37,6538 \mathrm{~b}(0)$ & $4,3263 \mathrm{~b}(0)$ \\
\hline
\end{tabular}

Perlakuan inokulasi ganda antara Glomus ACA dan PGPR memberikan pertumbuhan yang lebih tinggi dibandingkan dengan inokulasi tunggal Glomus ACA walaupun tidak berbeda nyata. Hasil ini sejalan dengan penelitian pada tanaman Stevia rebaudiana 60 hari setelah tanam (Vafadar et.al., 2013).

\section{KESIMPULAN}

Inokulasi tunggal Glomus ACA, Glomus SWM, PGPR, dan inokulasi ganda Glomus ACA + PGPR dapat meningkatkan pertumbuhan tinggi, diameter, berat kering akar, pucuk, total bibit $A$. crassna umur 8 bulan sebesar 127 , $128,94,-10 ; 51,52,39,1 ; 143,133,35$, 66; 174, 193, -48, 119; dan 164, 173, -44, 102 dibandingkan dengan kontrol. Sementara inokulasi tunggal Glomus ACA, Glomus SWM, PGPR, dan inokulasi ganda Glomus ACA + PGPR dapat meningkatkan pertumbuhan tinggi dan diameter tanaman muda A. crassna umur 6 bulan di lapang sebesar 67, 81, 23, 74; dan 56, 76, 18, 76 dibandingkan dengan kontrol.

\section{UCAPAN TERIMA KASIH}

Ucapan terima kasih disampaikan kepada teknisi Kelti Mikrobiologi Hutan Puslitbang Hutan: Sugeng Santoso, Najmullah, Ahmad Yani, Aryanto dan Herni yang telah membantu penelitian di tingkat pesemaian dan pekerjaaan laboratorium serta di lapang. Ucapan yang sama disampaikan kepada pegawai KHDTK Carita: Ateb, Roji dan yang membantu penanaman di lapang dan pengukuran pertumbuhan tanaman.

\section{DAFTAR PUSTAKA}

Almethyeb, M. S., Ruppel, H. M., Paulsen, N., Vassilev, B., \& Eichler-Löbermann Landbauforsch. (2013). Single and combined applications of arbuscular mycorrhizal fungi and Enterobacter radicincitans affect nutrient uptake of faba bean and soil biological characteristics. Appl Agric Forestry Res., 3(63), 229-234

Barden, A., Anak, N. A., Mulliken, T., \& Song, M. (2000). Heart of the matter: Agarwood use and trade and cites implementation for Aquilaria malaccensi (p. 49). Cambridge, UK: TRAFFIC International.

Brundrett, M., Bougher, N., Dell, B., Grove, T., \& Maljczuk, N. (1996). Working with Mycorrhiza in Forestry and Agriculture (p. 374). Canberra: ACIAR.

Constantino, M., Gomez-Alvarez, R., AlvarezSolis, J.D., Geissen, V., Herta, E., \& Barba, E. (2008). Effect of inoculation with rhizobacteria and arbuscular mycorrhizal fungi on growth and yield of 
Capsicum cinense Jacquin. Journal of Agriculture and Rural Development in the tropics and subtropics, 109(2), 169-180.

Cruz, R. E., de la Zarade J. F., Agganzae N. S., \& Lorilla, E. B. (1999). Differential mycorrhizal development of some agricultural, horticultural and forestry crops to inoculation of mycorrhizal fungi. In D. Jasper (Ed.). Proceedings of the International Symposium on management of Mycorrhizas in Agriculture, Horticulture and Forestry. Australian Institute of Agricultural Sciences, Australia.

Duryea, M. L., \& Brown, N. (1984). Seedling Physiology and Reforestation Success. Proceeding of The Physiology Working Group Technical Session. Boston: DR.W. Juck Publisher.

Eichler, B. , Caus, M., Schnug, E., \& Köppen, D. (2004). Soil acid and alkaline phosphatase in relation to crop species and fungal treatment. Landbauforsch Völkenrode, 54(1), 1-5.

Estaun, V., Camprubi, A., \& Calvet, C. (2003). Nursery and field response of olive trees inoculated with two arbuscular mycorrhizal fungi, Glomus intradices and Glomus mosseae. J. Amer. Soc. Hort. Sci., 128(5), 767-775.

Giovannetti, M., \& Mosse, B. (1980). An evaluation of techniques for measuring vesicular-arbuscular mycorrhizal infection in roots. New Phytol, 84, 489-500.

Irianto, R. S. B. (2015a). Efektifitas fungi mikoriza arbuskular terhadap pertumbuhan Alstonia angustiloba di pesemaian dan lapang. Submitted to Journal of Forest and Nature Conservation Research.

Irianto, R. S. B. (2009b). The effect of arbuscular mycorrhizal fungi and slow release fertilizer on the growth of Alstonia scholaris (L.) Br. seedlings in the nursery. Journal of Forestry Research, 6(2), 139147.

Irianto., R. S. B., \& Santoso, E. (2005c). Effect of arbuscular mycorrhiza fungi inoculation on teak (Tectona grandis linn. F) at Cikampek, West Java. Journal of Forestry Research, 2(2), 69 - 73.

IUCN. (2015). The IUCN the red list threatened species. Retrieved from http://www.iucnredlist.org/details/32814/0

Kannan, V., \& Sureendar, R. (2009). Synergistic effect of beneficial rhizosphere microflora in biocontrol and plant growth promotion. J. Basic Microbiology, 49, 158-164.

Plenchette, C., Fortin, J. A., \& Furlan, V. (1983). Growth responses of several plant species to mycorrhizae in a soil of moderate P-fertility. I. Mycorrhizal dependency under field conditions. Plant and Soil, 70(2), 199-209.

Richardson, A. E., Lynch, J. P., Ryan, P. R., Delhaize, E., Smith F. A., Smith S. E., ... Simpson, R. J. (2011). Plant and microbial strategies to improve the phosphorus efficiency of agriculture. Plant Soil, 349, 121-156.

Sall, J., Creighton, L., \& Lehman, A. (2005). JMP start statistic: A Guide to statistics and data analysis using JMP and JMP IN software (2nd ed.). SAS Institute publisher.

Setiadi, Y. (1999). Status penelitian dan pemanfaatan cendawan mikoriza arbuskula dan rhizobium untuk merehabilitasi lahan terdegradasi. Seminar Nasional Mikoriza I, 15-16 November 1999.

Shaharoona, B., Naveed, M., Arshad, M., \& Zahir, Z. A. (2008). Fertilizer dependent efficiency of Pseudomonads for improving growth, yield, and nutrient use efficiency of wheat (Triticum aestivum L.). Appl Microbiol Biotechnol, 79, 147-155.

Sieverding, E. (1991). Vesicular-Arbuscular Mycorrhiza Management in Tropical Agrosystem. GTZ.

Soehartono, T. (1997). Overview of trade in gaharu in Indonesia. In: Report of the third regional workshop of the conservation and sustainable management of Trees (pp. 2733), Hanoi, Vietnam. WCMC IUCN/SSC.

Thrane, C., Nielsen, T. H., Nielsen, M. N., Sørensen, J., \& Olsson, S. (2000). Viscosinamide - producing Pseudomonas fluorescens DR54 exerts a biocontrol effect on Pythium ultimum in sugar beet rhizosphere. FEMS Microbiol Ecol, 33, 139-146.

Turjaman, M., Tamai, Y., Santoso, E., Osaki, M., \& Tawaraya, K. (2006). Arbuscular mycorrhizal fungi increased early growth of two nontimber forest product species Dyera polyphylla and Aquilaria filaria under greenhouse conditions. Mycorrhiza, 16, 459-464.

Vafadar, F., Amooaghaie, R., \& Otroshy, M. (2014). Effect of plant-growth-promoting 
Jurnal Pemuliaan Tanaman Hutan

Vol 9 No. 3, November 2015, 149-158

rhizobacteria and arbuscular mycorrhizal fungus on plant growth, stevoiside, NPK, and chlorophyll content of Stevia rebaudiana. Journal of Plant Interaction, 9(1), 128-136.

Yasmin F., Othman R., Sijam, K., \& Saad, M. S. (2007). Effect of PGPR inoculation on growth and yield of sweetpotato. J. Biol. Sci., 7(2), 421-427. 